\title{
Cartografia de um serviço de atenção domiciliar e seus planos de visibilidade
}

| ' Sandra Maria Luciano Pozzoli, ${ }^{2}$ Luiz Carlos de Oliveira Cecilio |

Resumo: Cuidar de pessoas doentes em seus domicílios remete a tempos imemoriais, mas devido ao envelhecimento da população, houve crescente organização de tal prática, com serviços de atenção domiciliar. $\mathrm{O}$ objetivo desta pesquisa foi conhecer o processo de cuidado no Serviço de Atençáo Domiciliar de um município de médio porte no Estado de Sáo Paulo como componente da Rede de Urgência e Emergência. É um estudo de caso, qualitativo, usando a cartografia no campo de pesquisa. Também se realizaram entrevistas com cuidadoras e uma enfermeira hospitalar, e um grupo focal com enfermeiras da Atenção Básica. Para análise dos dados, a primeira aproximaçáo do material empírico foi a definição de "planos de corte" e em seguida dos "planos de visibilidade". Identificaram-se problemas relacionados a gestáo; limitaçôes no uso do sistema de informação; isolamento do Serviço de Atenção Domiciliar em relação aos demais serviços da rede de saúde; limitaçôes da Atenção Básica para apoiar efetivamente o serviço; sobrecarga do cuidador; e necessidade de estratégias de apoio.

> Palavras-chave: serviços de assistência domiciliar; serviços de saúde para idosos; políticas públicas de saúde.
1 Medicina Preventiva, Universidade Federal de São Paulo. São Paulo-SP, Brasil (sandrapozzoli@gmail.com). ORCID: 0000-0003-4916-6514.

${ }^{2}$ Medicina Preventiva,

Universidade Federal de São Paulo. São Paulo-SP, Brasil (luizcecilio60@gmail.com). ORCID: 0000-0002-9207-4781
Recebido em: 23/08/2019 Aprovado em: 29/10/2019 Revisado em: 25/06/2020 


\section{Introdução}

Há algumas décadas, países desenvolvidos que passam por um rápido processo de envelhecimento populacional investiram na atenção domiciliar como modelo assistencial substitutivo da internação hospitalar, com resultados menos onerosos, mais humanizados, seguros biologicamente, eficientes e inovadores. Nesse sentido, vários trabalhos apontam bons resultados em relação à assistência domiciliar, principalmente para pessoas idosas que necessitam de cuidados de longo prazo (TARRICONE; TSOUROS, 2008; OECD, 2005; GENET et al., 2011, 2012).

Nos países europeus, existem vários tipos de serviços de atenção domiciliar, que fornecem cuidados de apoio social, preventivos, curativos, de reabilitação ou paliativos, com especial atuação dos profissionais da enfermagem para pessoas idosas (SEIXAS et al., 2013).

No Brasil, os serviços de saúde com enfoque na atenção domiciliar se iniciaram timidamente em 1949, e estavam ligados a estruturas hospitalares visando à desospitalização. Com o tempo, esse tipo de assistência passou a ser desenvolvido em alguns municípios com um enfoque na integralidade da assistência (MENDES, 2001). Nesse sentido, em 2010, o Ministério da Saúde buscou organizar as Redes de Atenção à Saúde (RAS) no Sistema Único de Saúde (SUS), lançando algumas portarias com a finalidade de integrar as várias ações de saúde no sistema (BRASIL, 2010; FRANCO, FRANCO, 2003). Para compor a RAS, instituiu-se a Rede de Urgência e Emergência (RUE) em 2011, reformulando a Política Nacional de Atenção às Urgências e definindo a atenção domiciliar como um de seus componentes (BRASIL, 2011a). Poucos meses depois, houve a publicação de nova portaria instituindo um programa de atenção domiciliar, denominado "Programa Melhor em Casa" (PMC), com financiamento do Ministério da Saúde previsto diretamente para os municípios que apresentassem projetos de instalação ou implementação de Serviços de Atenção Domiciliar (SAD) (BRASIL, 2011a; 2011b). Após algumas alterações na legislação, a Portaria MS no 825, vigente desde 25 de abril de 2016, que regulava o programa de atenção domiciliar no país (BRASIL, 2016), foi absorvida pela Portaria de Consolidação no 5, de 28/09/2017, nos artigos 531 a 564, atualmente em vigor.

Para o PMC, a atenção domiciliar é definida como modalidade de atenção à saúde integrada à RAS, que prevê açôes de promoção, prevenção, tratamento, reabilitação 
e paliação prestadas no domicílio. O SAD é um serviço complementar aos cuidados oferecidos na Atenção Básica (AB) e nos serviços de urgência, substitutivo ou complementar à internação hospitalar. É composto por equipes multiprofissionais de atenção domiciliar (EMAD) e equipes multiprofissionais de apoio (EMAP). Como critério de inclusão, é necessário que o paciente esteja acamado, com quadro clínico estável e tenha um cuidador que seja responsável pelos cuidados diuturnamente (BRASIL, 2016). O PMC indica três modalidades de atenção domiciliar: Atenção Domiciliar tipo 1 (AD1), Atenção Domiciliar tipo 2 (AD2); e Atenção Domiciliar tipo 3 (AD3). Estas modalidades são definidas segundo a intensidade e complexidade de cuidados conforme a necessidade dos pacientes (BRASIL, 2013; 2016).

A modalidade AD1 é destinada aos usuários com indicação de atenção domiciliar que estão em condição estável, que requerem menor frequência e menor necessidade de intervenções multiprofissionais e que tenham cuidados supridos por seus cuidadores. A assistência deve ser feita por unidades da AB, ou seja, Unidades Básicas de Saúde (UBS) e Unidade Saúde da Família (USF) com o apoio do Núcleo de Apoio à Saúde da Família (NASF), dos Ambulatórios Médicos de Especialidades (AME) e de Reabilitação (BRASIL, 2016). A modalidade AD2 atende usuários com indicação de atenção domiciliar para abreviar ou evitar a hospitalização, que necessitem de cuidados frequentes como tratamentos parenterais, cuidados sequenciais e intensificados para pacientes com doenças agudas ou crônicas e cuidados paliativos. E a assistência deve ser realizada também pelo SAD, no mínimo uma vez por semana, com apoio da RUE (BRASIL, 2016). A modalidade AD3 assiste pacientes com necessidade de cuidado multiprofissional mais frequente, com uso de equipamentos ou procedimentos de maior complexidade como ventilação mecânica, paracentese, nutrição parenteral e transfusão de sangue, que demandem períodos maiores de acompanhamento domiciliar e devem ser assistidos pelo SAD, com apoio da RUE (BRASIL, 2016). Alguns municípios, na época da implantação do PMC, já mantinham serviços domiciliares com variados desenhos, como no caso do serviço do município estudado.

O objetivo principal desta pesquisa foi conhecer o processo de cuidado num SAD como componente da RUE e, especificamente, acompanhar sua gestáo e produção do cuidado, compreender o processo de cuidado e sua interligação com a rede de $\mathrm{AB}$, identificando seus limites e possibilidades como modelo de atenção principalmente para a população idosa, acamada, portadora de doenças crônicas. 


\section{Percurso metodológico}

Esta pesquisa é um estudo de caso de um SAD em um município de médio porte no Estado de São Paulo, com população estimada para 2015 de 233.249 habitantes (SEADE, 2017). É um estudo qualitativo, usando a abordagem cartográfica.

A cartografia é derivada do pós-estruturalismo francês influenciada por Foucault, Deleuze e Guattari; no Brasil, foi trabalhada primeiramente por Rolnik (1989). A cartografia possibilita que o pesquisador vivencie no campo de pesquisa os fenômenos em sua multiplicidade, colaborando para análises das mutaçóes sociais, da processualidade e suas transformações (SOUZA; SOUZA, 2014; KASTRUP, 2007). Considera-se, assim, que a cartografia é uma forma de pesquisa intervenção, pois nenhuma das partes envolvidas sai inalterada, devido ao encontro entre as pessoas, acarretando transformação também no processo de trabalho (SAFFER; BARONE, 2017).

Após um primeiro contato com a coordenadora do SAD para compreender a realidade do serviço, houve um convite para participarmos das atividades diárias das equipes e acompanharmos o processo de trabalho, resultando na presente cartografia. Participaram duas equipes tipo EMAD e uma EMAP, totalizando 29 profissionais incluídos os temporários. A inserção no campo ocorreu no período de 15/01/2015 a 06/08/2015, uma vez por semana, oito horas por dia, totalizando 176 horas de vivência, acompanhando os profissionais nas visitas domiciliares e na rotina de trabalho.

O diário de campo foi um instrumento fundamental para registro das experiências, observações e reflexôes vivenciadas no campo de intervenção. Além desse instrumento, foram levantados dados secundários do SAD, em prontuários e planilhas de controle de visitas das equipes para conhecer o universo da produçáo.

Para conhecer a relação do $\mathrm{SAD}$ com a $\mathrm{AB}$, principalmente em relação à operacionalização da $\mathrm{AD} 1$, foi organizado um grupo focal com oito enfermeiras que atuavam na $\mathrm{AB}$, das quais três trabalhavam em UBS e cinco em USF. No período de inserção no campo, conheceu-se no município um serviço de internação domiciliar da Santa Casa de Misericórdia que atendia pacientes do SUS, promovendo a desospitalização em determinadas situaçôes. Considerando a relação com o objeto de estudo, foi realizada uma entrevista com a enfermeira coordenadora do referido serviço, denominado Departamento de Atendimento Domiciliar (DAD). Completando a 
pesquisa, foram realizadas entrevistas semiestruturadas com cinco cuidadoras de pacientes usuários do SAD para conhecer suas vivências e suas avaliaçóes do serviço.

Como estratégia de análise dos dados, a primeira aproximação adotada foi a definição de "planos de corte" para uma primeira sistematização do material empírico, o que se pode considerar como os analisadores da política. Por meio de extensiva leitura do material registrado, foram definidos os "planos de corte", que correspondiam aos aspectos presentes na Política de Atenção Domiciliar, referindose à "governança da política", mais especificamente, suas recomendaçóes e diretrizes, tendo como balizador os objetivos propostos na pesquisa (MELUCCI, 2005; ALTOÉ, 2004, LAPASSADE, 2005). Dessas opçōes resultaram quatro "planos de corte": 1) A moldura da gestão municipal e os limites da gerência; 2) A produção da equipe; 3) O binômio paciente/cuidador; e 4) O SAD nas redes de atenção.

$\mathrm{Na}$ segunda aproximação analítica, foram evidenciados planos de visibilidade mais expressivos dentro dos planos de corte. Os planos de visibilidade resultaram da conexão de várias cenas registradas que guardavam algu ma relação entre si, e, quando conectadas, revelavam elementos importantes do cotidiano do trabalho das equipes, nem sempre visíveis quando "olhados de fora". Esse é um mérito da abordagem cartográfica. Os planos vão adquirindo visibilidade a partir das "conexôes de cenas", mostrando as relaçôes inter-humanas e suas intensidades, que afinal resultam no cuidado em saúde e/ou nas relaçôes internas à equipe.

Dentro de cada plano de visibilidade há, em diferentes cenas, o entrecruzamento dos analisadores ou das "preocupaçôes" ressaltando elementos do "mundo que fica de fora", ou seja, tudo aquilo que escapa a todas as estratégias de gestáo (CECILIO et al., 2014). O material produzido no campo foi analisado considerando as indicaçóes das políticas públicas que envolvem a atenção domiciliar e as redes de atenção à saúde, mas sempre com intenção maior de iluminar pontos importantes da vivência do cuidado domiciliar e dar voz às pessoas envolvidas em todo processo de cuidado no domicílio. Um estudo, portanto, com clara opção metodológica de dar visibilidade a aspectos micropolíticos do cuidado em saúde, no caso, em um SAD.

Este estudo foi aprovado pelo Comitê de Ética em Pesquisa da Universidade Federal de São Paulo (UNIFESP), registrado com o CAAE 39179014.0.0000.5505 e Parecer no 907.048, de 16/12/2014, atendendo às exigências da Resolução no 466/12 do Conselho Nacional de Saúde. Todos os sujeitos da pesquisa leram e assinaram o Termo de Consentimento Livre e Esclarecido; os nomes dos pacientes e cuidadores 
usados no presente artigo são fictícios para preservar a identidade dos mesmos. $\mathrm{O}$ nome do município foi substituído pela letra "X" para preservar a identidade dos profissionais de saúde envolvidos na pesquisa, visto tratar-se de um estudo de caso.

\section{Resultados e Discussão}

O SAD do município "X" atuava desde 1997 por iniciativa municipal, mas no final do ano de 2012 foi habilitado para o Programa Melhor em Casa (PMC). Conforme levantamento realizado na planilha de pacientes do serviço na época do estudo, o SAD atendia 172 pessoas, predominando a população feminina 112 (65,11\%), idosa 141 (81,97\%) entre 60 e 101 anos, que provinham, em sua maioria, de pós-internações do principal hospital da cidade, a Santa Casa de Misericórdia. Os pacientes acamados eram tipo $\mathrm{AD} 1$ ou $\mathrm{AD} 276(44,18 \%)$ e não foram identificados pacientes tipo $\mathrm{AD} 3$, ou seja, com maior complexidade de cuidados.

Também foi possível conhecer que 132 (76,74\%) usuários eram portadores de uma a duas doenças e $42(24,41 \%)$ apresentavam mais de três doenças concomitantes. As doenças respiratórias e cardiovasculares eram mais prevalentes, com destaque para as doenças respiratórias, pois $96(55,81 \%)$ pacientes atendidos pelo SAD eram usuários de concentrador de oxigênio, não acamados, devido ao fornecimento do compressor de oxigênio ser feito por esse serviço no sistema de saúde municipal e aqui já há um desvio na função do SAD.

Quanto aos profissionais, estes estavam em número insuficiente, em relação ao preconizado pelo $\mathrm{PMC}$, sobretudo em relação aos profissionais enfermeiro, fisioterapeuta e assistente social. Quanto ao plano de corte "A moldura da gestão municipal e os limites da gerência", foram identificados os planos de visibilidade: "Os limites da gerência" e "Gaps na informação e a angústia na produção de dados".

Em Os limites da gerência”, ficaram evidentes as dificuldades administrativas em relação à insuficiência de recursos humanos e de recursos materiais.

Ao final daquela primeira tarde reuni com Enf. $(\mathrm{Z})$ e Enf. $(\mathrm{H})$, elas falavam sobre as dificuldades enfrentadas para levar avante o SAD, queixavam-se da falta de recursos humanos e da falta de apoio da secretaria municipal de saúde, que estava no seu sexto secretário de Saúde com dois anos de mandato municipal - eleiçóes de 2012. (Cena registrada em 15/01/2015).

[...] (Z) está em reunião com a nova coordenadora regional para tentar resolver alguns problemas mais urgentes como a falta de carro e de motorista no SAD. (Cena registrada em 24/04/2015). 
A grande dificuldade da gerência do SAD era manter o número suficiente de profissionais para a assistência durante todo o período de trabalho. O "apoio" referido está relacionado ao deficiente número de aspiradores e concentradores de oxigênio, não ter os equipamentos e materiais necessários à assistência, além da ausência de programas de educação permanente em saúde (EPS) para os profissionais.

A cena a seguir indica a crise de governabilidade e governança que o município estava passando, atingindo os serviços de saúde.

(Z) comenta na reunião de equipe que o orçamento para contrataçáo de pessoal já chegou no limite da Lei de Responsabilidade Fiscal e náo há possibilidade de chamar os aprovados do último concurso para preenchimento de vagas pois este foi anulado. (Cena registrada em 30/04/2015).

Segundo Torres (2016), a crise de governabilidade e governança envolve conceitos das dimensôes fiscal, administrativa e de legitimidade.

Em "Gaps na informação e a angústia na produção de dados", foram perceptíveis as dificuldades para inserção de dados no sistema de informação denominado Registro de Açôes Ambulatoriais de Saúde da Atenção Domiciliar (RAAS-AD), por falta de capacitação dos profissionais, de rotina e continuidade na inserção dos dados, além de limitação do próprio sistema para operacionalização e análise das informaçôes.

Em uma conversa, $(\mathrm{P})$ demonstra preocupação em relação à suspensão dos recursos do Ministério da Saúde para o SAD, devido à falta de preenchimento da RAAS-AD por dois meses consecutivos. Ela diz que depende de um funcionário da Secretaria de Saúde, que deve comparecer mensalmente ao SAD para fechar o sistema de um mês e abrir para o próximo mês, porém ele não tem feito essa visita mensal. Além disso, devido à licença $\mathrm{e}$ férias de $(\mathrm{P})$, os prontuários não foram incluídos na produção dos meses anteriores; desde outubro há fichas para serem inseridas. (Cena registrada em 20/02/2015).

O registro dos atendimentos no sistema de informação é imprescindível, pois esse sistema opera como um "controle" da produção do SAD, a fim de que o Ministério da Saúde mantenha o município habilitado para o desenvolvimento da atençáo domiciliar, com repasse de recursos fundo a fundo. Na tentativa de melhorar a qualidade dos dados, durante o ano de 2015, houve a mudança para o Sistema de Informação em Saúde da Atenção Básica - Atenção Domiciliar (SISAB-AD) (BRASIL, 2015).

Outra questão refere-se à organização dos prontuários e anotaçóes das visitas realizadas, as quais pareciam ser consideradas pelos profissionais mera obrigação 
do trabalho prescrito. Esse problema também foi identificado em outros trabalhos como em Feuerwerker e Merhy (2008).

Em outra reuniẫo: $(Z)$ comenta que percebeu na atualização da planilha de pacientes da equipe 1 que há prontuários sem anotação de enfermagem. Falta verificar a equipe $2 \mathrm{e}$ orienta que as anotaçóes de enfermagem devem ter horário. Refere que encontrou muitos prontuários com rasuras. (Cena registrada em uma Reunião de Equipe em 21/05/2015)

[...] à tarde, terminado o levantamento dos tipos de admissão, passei a verificar os prontuários das "altas", para conhecer para onde foram encaminhados os pacientes e quantos saíram do SAD por cura. Não consegui avançar muito, logo no primeiro prontuário não havia anotação de alta, fui perguntar à $(Z)$, nisto (E) ouviu e disse que era um óbito. Estava arquivado na pasta errada. (Cena registrada em 02/06/2015).

No plano de corte "A produção da equipe" os planos de visibilidade evidenciados foram: "Os bastidores da atenção domiciliar: os micropoderes", "As precariedades constitutivas do cotidiano de trabalho" " "A equipe cuidando".

No plano de visibilidade "Os bastidores da atenção domiciliar: os micropoderes", há o empenho da gerência em organizar o planejamento de cuidados de cada equipe, por meio de uma planilha; e as "provocaçôes" dos vários profissionais à gerência, impondo suas autonomias (principalmente os médicos), confrontando com a autoridade da gerência em alguns momentos.

Em outra oportunidade notei que o Dr. (A) não veio e pergunto para (D) sobre o médico. responde: Não, ele não veio! Tá séria a coisa! Ele também está atrapalhando! Além de não ter carro ele também não vem para resolver os problemas que tem com nossos pacientes, tá sério! (Cenas registradas em 23/04/2015).

Além disso, transpareceu a recorrência de regimes de regulação clientelística como a influência de políticos no acesso ao serviço.

Dr. (A) chega e é chamado por (Z) em sua sala para passar um caso de uma senhora que estava com febre e a família apelou a um vereador para conseguir o atendimento domiciliar. Além deste caso tem outras duas visitas, mas, Dr. (A) dá prioridade para o caso político. (Cena Registrada em 12/03/2015) [...]

Outra questão é a necessidade de ter o profissional enfermeiro com um perfil próprio para atuar em equipe multiprofissional, para o exercício do planejamento de cuidados multiprofissionais, ou seja, aquele que "puxa" a discussão de um plano de cuidados individual entre os profissionais.

Num final de tarde, a gerente recebe uma reclamação de (D) sobre o comportamento acomodado da Enfa (U). 
(D) refere que (U) é muito lenta, sem iniciativa, náo ajuda nos curativos; fica sentada vendo (D) e (G) trabalharem. A gerente concorda e diz que a observou na casa de D. Rita, mas pede para aguardarem um pouco mais. (Cena registrada em 02/06/2016).

A forte influência dos profissionais na modelagem e gerência do serviço aponta para a necessidade de posturas mais negociadas por parte do gerente para enfrentar os problemas cotidianos propiciando um ambiente de comunidade, ou de diálogo, que favoreça o processo de cuidar (DEJOURS et al., 1994).

No plano de visibilidade "As precariedades constitutivas do cotidiano de trabalho", evidenciou-se a falta de vários elementos fundamentais como: pessoal (enfermeiros, auxiliares de enfermagem, médicos, motoristas, fisioterapeutas, nutricionistas); material (carros, medicamentos, dietas, fraldas, materiais de curativos, camas hospitalares, cadeira de banho, cadeira de rodas, andadores, aspiradores e concentradores de oxigênio) e condiçôes de apoio (educação permanente com discussões clínicas em diversas áreas como fisioterapia, enfermagem e médica).

À tarde não há médico na equipe 1; a técnica de enfermagem (D) e a enfermeira (H) saem para visita de acompanhamento. (Cena registrada em 15/01/15).

[...] As duas equipes estão completas, porém não podem sair porque tem carro, mas não tem motorista. (Cena registrada em 06/04/2015).

[...] Em uma visita domiciliar: A cuidadora conta sobre sua rotina de cuidados e diz que precisa de uma cama hospitalar, pois sua coluna náo aguenta mais. A Enfa $(\mathrm{H})$ orienta que esse recurso a Prefeitura não oferece e informa que ela pode alugar por convênio com a Funerária. A cuidadora informa que o convênio que tem com a Funerária não cobre cama hospitalar, o assunto acaba sem solução. (Cena registrada em uma Visita Domiciliar em $10 / 02 / 2015)$.

Apesar de todas as dificuldades cartografadas, que geravam sofrimento aos trabalhadores, havia grande empenho da maioria dos profissionais nos atendimentos domiciliares. Por outro lado, talvez pelo fato de as limitaçóes vivenciadas comporem a normalidade do cotidiano, algumas açôes que poderiam ser realizadas (como o agendamento de consultas em especialidades no ambulatório, ou agendamento de ambulância para transporte de paciente acamado), não eram percebidas pelos profissionais do serviço como açôes possíveis de serem feitas.

Em "A equipe cuidando", foram cartografados encontros com os cuidadores e a atuação dinâmica e atenciosa dos profissionais das EMAD permeadas pelo diálogo e orientaçôes aos cuidadores e pacientes idosos. Também houve acompanhamento à distância com telefonemas realizados pelo médico da equipe ou pelas auxiliares e 
técnicas de enfermagem, para monitorar as condiçôes de saúde dos pacientes; assim como a participação do pesquisador no processo de trabalho com a equipe, vivendo um momento de "obra coletiva", que contava com a contribuição de cada um na construção da história do serviço de saúde ou da organização, segundo Campos (2000), como vemos na cena a seguir:

Em uma visita ao domicílio: - Eu estava próximo à perna da paciente, calcei luvas e ajudei a segurar a perna para (E) fazer a limpeza, enquanto (F) fornecia os materiais. Ao final, percebia o olhar de satisfaçáo de (E) e (F) com o meu envolvimento no cuidado. (Cena registrada em 06/04/2015).

Para Campos (2000), o uso dos conceitos de "núcleo" e "campo" de responsabilidades profissionais que atuam num processo de trabalho interdisciplinar tem sido um bom dispositivo para analisar o trabalho em equipe. Assim, o conhecimento mais específico de cada profissional é considerado "núcleo", e o espaço de interseção, de confluência, em que os conhecimentos se fundem, é considerado “campo". A seguir, cenas de atuação de cada núcleo profissional.

Acompanho uma visita ao Sr. Isaías, 77 anos - PO tardio de cirurgia abdominal, com colostomia e escaras, está acamado em cama hospitalar, há dois meses em casa, sua cuidadora é a esposa idosa. Ele apresenta febre, a auxiliar de enfermagem $(G)$ toma à frente da equipe e faz as orientaçóes necessárias, responde as dúvidas da cuidadora e após realizarem os curativos nas escaras orienta chamar o SAMU e levá-lo à UPA para avaliação médica e fazer um RX de tórax para investigarem esta febre. A cuidadora concorda. (Cena registrada em uma visita domiciliar em 20/02/2015) [...]

tarde visitamos D. Aparecida, 87 anos, AVC, deitada em uma cama hospitalar e recebendo dieta enteral, a mesma não se comunica, encontramos duas filhas da paciente cuidando dela. (D) verifica os sinais vitais. Dr. (L) procurou conversar com os familiares da Sra. Aparecida tentando entender todo o processo de adoecimento, avaliou a paciente, fez exame físico e fez suas anotaçóes. Deixou as receitas necessárias para a paciente e se colocou à disposição da família explicando que a partir daquela data irá acompanhá-la. A família pareceu satisfeita. (Cena registrada de uma visita domiciliar em 29/07/2015).

No plano de corte "Binômio paciente-cuidador", vislumbram-se os planos de visibilidade: "O universo da perda da autonomia: o acamado", "O universo do cuidador" e "O ponto de vista do cuidador".

Em "O universo da perda da autonomia: o acamado", focalizando o paciente, sobressaiu-se a vivência da vulnerabilidade humana em diferentes perspectivas: social, ética e cultural (TORRALBA I ROSELLÓ, 2009). Como vemos na cena a seguir:

Fomos à casa de D. Rita, 84 anos, mora sozinha e tem úlcera varicosa no MID, que limita seus movimentos por permanecer com a perna enfaixada. A ferida é extensa e com secreção 
purulenta. (D) e a Enfa (H) fazem o curativo. A sra. Rita está repetitiva na conversa e esquecida dos momentos atuais. Na casa tem um senhor que está cortando o mato no fundo da casa, ele é um vizinho. A sobrinha não compareceu ao encontro marcado previamente pela assistente social (R). Surge, passando em frente à casa, uma senhora conhecida de D. Rita, ela entra na casa e, após entender quem somos fornece um número de telefone para (R), que é de uma outra sobrinha de D. Rita.

(R) tentou contato por celular com essa sobrinha, mas ela desligou o telefone no meio da conversa. (R) conversa com D. Rita com calma, tentando explicar que ela não pode ficar sozinha em casa e precisa de alguém para fazer curativo e cuidar dela. Durante a conversa fica sabendo que D. Rita "ajuda" com dinheiro a sobrinha inscrita como cuidadora. A equipe vai conhecer as condições de vida da paciente e constata que só tem arroz, feijão e farinha de milho para comer; tem muitas batatas podres numa fruteira e a geladeira está vazia. No tanque, havia várias faixas-crepe para lavar e roupas sujas. Aquela conhecida que havia entrado para falar conosco, se comprometeu a fazer o almoço naquela manhá para D. Rita e ver se na Pastoral da Saúde alguém poderia vir trocar o curativo diariamente. Nos despedimos. (Cena registrada em 15/01/2015).

[...] Visitamos a paciente D. Maria, 86 anos, acamada, atrofiada por sequela de AVC, ela não responde ao ser chamada. A cama da paciente é comum e muito baixa, as condiçóes de moradia são muito precárias. A cuidadora é a irmã de 76 anos e diz que dá banho em D. Maria duas vezes na semana e, troca os curativos dos pés a cada dois dias, onde surgiram escaras devido ao ato de esfregar os pés. A cuidadora refere que a paciente não está se alimentando bem, acha que a sonda para alimentação pode ajudar. Conta que está sozinha para cuidar de sua irmã e está cansada. Seu marido é alcoolista, não a ajuda e ainda causa diversos problemas. (Cena registrada em 01/06/2015).

A realidade mostrou cuidadores que negligenciavam seus dependentes, portanto, náo poderiam assumir o papel de cuidador; geralmente eram idosos cuidando de idosos, o que resultava em um verdadeiro "quebra-cabeças" a ser administrado pelo SAD, nos quais a dimensão "social" do cuidado ficava muito evidente, sendo desafiador para as equipes.

Em “O universo do cuidador", tornou-se evidente a solidão do cuidador no cuidado, ressaltando a necessidade de se pensar em outros serviços de apoio ao cuidador, com diferentes arranjos sociais, bem como o valor que tem o grupo de cuidadores como espaço de intervenção e acompanhamento de sua saúde física e mental. Nas cenas que se seguem, ressaltam-se a solidão e a sobrecarga do cuidador.

Fomos à casa de uma senhora idosa, D. Maria, 80 anos, teve um AVC há oito anos e tem sérias sequelas. É cuidada por um de seus 9 filhos, ele é solteiro, cerca de 45 anos e náo trabalha para cuidar da mãe. Preocupado com um prurido que surgiu no quadril de sua mãe, pede à Enfa $(\mathrm{H})$ que olhe o local, $(\mathrm{H})$ resolve pedir uma avaliação do médico da manhá. Pergunto ao cuidador se alguém o ajuda na rotina e ele responde conformado que suas 
irmãs trabalham, por isso não tem ajuda. Após a visita, já no carro, a auxiliar (D) comenta: “É! Uma mãe cuida de dez filhos, mas dez filhos não cuidam de uma mãe!" - fala indignada com a situação do cuidador ser sozinho no cuidado. (Cena registrada em 15/01/15).

[...] É! Às vezes o limite nosso não é tanto o físico, mas é o psicológico, de estar ali e não poder fazer nada. De ouvir o gemido, o grito e náo poder ajudar! Às vezes a única coisa que podemos fazer é mandar uma mensagem lá pra cima, só Deus! [...] Esse é o meu maior sofrimento! E hoje eu estou conseguindo, mas às vezes não consigo, todo dia vendo aquilo, é difícil! É difícil a gente superar! (Cena registrada em um grupo de cuidadores, a fala de uma cuidadora, em 02/04/2015).

Em "O ponto de vista do cuidador", foi possível "ouvir" o que os cuidadores pensam do SAD, trazendo seus elogios e críticas, ressaltando a necessidade de trabalhar com a equipe integrada, principalmente em visitas de avaliação e a necessidade de melhorar a formação dos profissionais de saúde para atuarem no domicílio.

[...] Rosa: Olha! Eu vou te falar, da equipe do médico, das enfermeiras, eu achei excelente, sabe!? O atendimento. Mas da fisioterapeuta eu não sei. Ah! eu achei meio fraca, não sei por que demorou muito pra vir! Ah! Ela estava afastada! [...] Mas se eu tivesse ficado esperando, se eu não tivesse a iniciativa de pagar [fisioterapeuta], talvez minha mãe não estaria andando ainda! Não é? Porque essa outra que eu paguei, ela vinha com a bola, sabe, e a da Prefeitura não! Era bem assim! Bem, Vixe! Fraquinha! [...] O médico e as enfermeiras uma graça! Isso foi 10! [...] (Transcrição de entrevista com a cuidadora Rosa em 09/10/2015).

Apesar das dificuldades, os cuidadores não permanecem parados diante das limitaçóes da equipe do SAD, buscam ativamente outros profissionais e/ou serviços que possam resolver os gaps percebidos, confirmando que a população compóe seus "mapas de cuidados", como bem estudado por Cecílio et al. (2014), produzindo um verdadeiro mix público-privado, tentando suprir as necessidades de serviços para manutenção da saúde.

[...] tudo que eu faço é pelo SUS. [...] só as vezes faço uma consulta particular! Eu sempre levo, umas duas vezes por ano, no Dr. D., porque aí eu pago né! Eu acho que você ficar dependendo [...] pessoa idosa é que nem criança, né?! E se depender do posto demora! (Entrevista com a cuidadora Rosa em 09/10/2015)

[...] por exemplo, elas [as sessões de fisioterapia] poderiam ser estendidas. Essa equipe que tem fisioterapeuta, enfermeiro, médico, eles poderiam vir de três em três meses, ter essa frequência. [...] E cada um, trocar inclusive ideias! A fisioterapeuta, com o médico, com a enfermeira, trocar ideias! - O que a gente poderia fazer pela D. Hilda? Certo?

A cama que eu comprei pra Hilda, essa cama motorizada, eu fiz a pesquisa sozinha [na internet], sendo que alguém poderia ter me ajudado! [...] (Entrevista com a cuidadora Iva em 23/06/2015) 
Por fim, o plano de corte "O SAD nas redes de atenção" vislumbrou os planos de visibilidade: "A (in)composição com a Rede de Atenção à Saúde", "A Atenção Básica: lugar de impotência" e "O hospital: construindo outra perspectiva de atenção domiciliar no municipio".

Em "A (in)composição com a Rede de Atenção à Saúde", foi possível caracterizar o isolamento que o $\mathrm{SAD}$ vivia na rede de serviços, pois não haviam articulaçóes administrativas e políticas para construçáo efetiva da RUE, prevalecendo as incursôes tímidas dos próprios profissionais e da gerente do serviço para estabelecer relaçôes com outros serviços, visando a continuidade e integralidade do cuidado.

(Z) informa a equipe do SAD que a Odontologia do Centro de Especialidades Odontológicas (CEO) participará da assistência aos pacientes do SAD e já encaminhou uma lista de pacientes para os dentistas se organizarem. (Cena registrada em uma Reuniáo de Equipe em 21/05/2015).

Por outro lado, os profissionais do SAD não admitiam mudanças em seus horários de trabalho para colaborar na construção do cuidado integral de seus pacientes.

Conversando com as duas fisioterapeutas sobre a organização do SAD, lancei a questão da necessidade de plantáo no SAD para atender em finais de semana e feriados, mas (I) rebate esta ideia, afirmando que o SAD não fará plantão. Segundo ela, teria que fazer uma parceria com a UPA ou o SAMU para dar sequência em tratamentos como antibioticoterapia ou outro tipo de assistência. E, afirma que de certa forma essa conversa não está pactuada com a Coordenadora da Atençáo Básica. (I) afirma que a rede não se conversa, não é uma teia. (Cena registrada em 02/04/2015).

A legislação que instituiu o PMC deixa aberto o tempo de assistência e os critérios para inclusão no programa, em cada nível de atenção (AD1, AD2 e AD3), que podem ser interpretados de diferentes maneiras pelos gestores municipais e seus gerentes de serviços. Contraditoriamente, o sistema de informação adotado pelo programa estabelece critérios rígidos para inclusão e seguimento de cada paciente, o qual é usado com rigor para justificar os repasses de verba do Ministério da Saúde para o município.

A falta de mais profissionais trabalhando no SAD impedia que o serviço atuasse em esquema de plantão à distância, em finais de semana ou à noite, sobrecarregando os cuidadores em casos de emergência, que precisavam acionar o Serviço de Atendimento Médico de Urgência (SAMU) ou Unidade de Pronto Atendimento (UPA) naqueles períodos. Mas também se observou em conversa com alguns profissionais a não aceitação desse tipo de acompanhamento à distância, em horários alternativos de trabalho. 
Em "A Atençâo Básica: lugar de impotência”, confirmou-se a precária realidade da $\mathrm{AB}$, composto por UBS e USF, as quais deveriam realizar a $\mathrm{AD1}$ para assistir doentes crônicos acamados. Evidenciou-se a desestruturação da $A B$ no sistema de saúde pela falta de recursos humanos, meios de transporte e materiais de consumo.

As enfermeiras que atuavam em UBS apresentaram, no grupo focal, as diversas dificuldades para prestar assistência nos domicílios em caso de pessoas acamadas; expressaram, com pesar, a impossibilidade de saírem das unidades devido à falta de transporte, mas também a falta de recursos humanos, condiçôes que inviabilizam a realização da $\mathrm{AD} 1$.

Também nesse momento se reforçou a sobrecarga do cuidador e da família em relação ao cuidado de pessoas dependentes por longo prazo e os arranjos efetuados para constituir o mapa de cuidado necessário.

A gente está com falta de recursos humanos já vem de longa data, é falta de material, de recurso material, entâo a gente está trabalhando com o que a gente tem, com as possibilidades existentes no momento! E, assim, eu me sinto muito fragilizada neste sentido. Porque a gente não tem apoio, não tem reforço, não tem orientação, não tem um Norte a seguir, eu acho que é isso que está faltando dentro da Prefeitura! (Transcrição de gravação do Grupo Focal - Enfa. 8 - USF) [...]

Existem casos, na minha unidade a gente não tem mais o apoio do NASF, então precisa de fisioterapia. Os familiares, às vezes, até tentam, mas eles também acabam não conseguindo, alguns reúnem e pagam um profissional particular, quando pode, mas não atende tudo no Melhor em Casa! (Enfa. 2 - USF)

Ficou evidente a importância do SAD e do sistema de saúde como fornecedores de materiais para o cuidado diário do paciente, contribuindo para diminuir os gastos financeiros da família do doente acamado.

A minha área é muito grande, minha área é muito extensa, eu não tenho pernas para acompanhar, são muitos acamados, a gente tem mais de 100 pacientes cadastrados para fraldas geriátricas, dieta enteral adulto. [...] E isso são os que vêm pegar, fora os que não vem! Então a gente não tem pernas para acompanhar mesmo! (Transcrição do Grupo Focal - Enf 4 - UBS).

[...] Se você me perguntar quantos acamados tem na minha área, eu não sei te informar e nem sei quantos são atendidos! Eu só sei pela quantidade de pacientes que vem pegar material na UBS, que eu tenho mais de 40, só sei essa parte, e nem sei te dizer se esses 40 são os mesmos que são atendidos pelo [SAD]. [...] a única coisa que eu tenho é assim, tipo, ele deu alta (do hospital) e mandou procurar a UBS, aí eu abraço aquele usuário apenas para fornecer o material necessário para um curativo, as fraldas, [...] o único contato que eu tenho é com o familiar que vem naquele momento pegar o material, é esse o contato que eu tenho. (Transcrição do Grupo Focal - Enfa 6 - UBS). 
Em "O hospital: construindo outra perspectiva de atenção domiciliar no município", foi possível conhecer um serviço de internação domiciliar organizado para os pacientes usuários do SUS, completando assim o conhecimento da RUE com a atuação do principal hospital do município "X".

Por meio de uma entrevista, a enfermeira coordenadora do serviço de internação domiciliar apresentou os motivos que levaram a administraçấo do hospital a iniciar esse serviço. Com o objetivo de humanizar o atendimento e acelerar a rotatividade dos leitos hospitalares, criou-se o Departamento de Atendimento Domiciliar (DAD), que ao final, favoreceu a dinâmica financeira da instituição e diminuiu os casos de infecção hospitalar.

Esse serviço ganhou a simpatia dos usuários e médicos do hospital, funcionando em uma lógica mais dinâmica, como por exemplo, a equipe de enfermagem dirigindo o carro e seguindo um planejamento conforme os horários das medicaçôes prescritas.

[O DAD] surgiu em fevereiro de 2014, por conta da necessidade de rodar leito, girar! Toda a questão da humanização, da desospitalização do paciente e aí agregou a necessidade de rodar leitos! Nós somos o único hospital aqui na cidade com essa capacidade de leitos [...] São 230 leitos. [...] O foco do DAD é aquele paciente bem clinicamente, estável, mas que fica internado um tempão por conta de concluir doses de antibióticos, que é uma coisa restrita ao hospital! [...] Paciente que já estava bem clinicamente, mas ficava aí! Então a gente começou a rastrear quais eram esses pacientes e surgiu o DAD, inicialmente muito tímido, até a gente conseguir ganhar confiança do corpo clínico. [...] conseguimos o carro através da prefeitura [...] (Transcrição de gravação da entrevista com Enfa. VN da Santa Casa).

Importante destacar que a decisão de implantar esse serviço de internação domiciliar não foi discutida com os demais serviços que compóem a RUE, mostrando a falta de articulação e reforçando o isolamento de cada serviço na RAS, dificultando a integralidade do cuidado.

\section{Considerações finais}

A atenção domiciliar é um modelo de atenção à saúde que está em desenvolvimento na realidade do SUS e na rede de saúde suplementar e hospitais privados, os quais vêm, crescentemente, investindo em serviços de internação domiciliar. Sendo um estudo da instância micro, por se tratar de um estudo de caso, optou-se por usar uma metodologia advinda do pós-estruturalismo, a cartografia, a qual viabilizou um tipo de abordagem no campo de pesquisa mais próximo das pessoas protagonistas 
daquela realidade, ou seja, os trabalhadores da saúde, os cuidadores e os doentes, tendo o ambiente social como moldura.

A abordagem cartográfica permite que o pesquisador se aproxime das pessoas que constroem a realidade, participando com elas de sua rotina e compreendendo os problemas que ocorrem, "vivenciando com". Como contribuiçóes, a pesquisa desvela elementos micropolíticos presentes no trabalho cotidiano da equipe de um $\mathrm{SAD}$, quase nunca visíveis (e valorizados) pela gestão, e sempre mais complexos e matizados do que os ditames postos pela política oficial do Ministério da Saúde. Essa "disjunção" entre a formulação das várias políticas pelo Ministério da Saúde e sua operacionalização já tem sido apontada por outros estudos.

A presente pesquisa reforça a importância do "momento gestão" das políticas de saúde, com especial ênfase para a necessidade de criação de arranjos organizacionais facilitadores da escuta e participação dos trabalhadores diretamente envolvidos com o cuidado. Aponta os limites da AB como coordenadora do cuidado, tal como tem sido posto pela Política Nacional de $\mathrm{AB}$, por não reunir condiçóes de governança/ governabilidade para tanto, como também já tem sido apontado por outros estudos.

Sem desconsiderar a importância da $\mathrm{AB}$ na construção de redes de atenção, o estudo indica a necessidade de arranjos mais complexos envolvendo vários serviços e instâncias de gestão locorregional, para dar conta das complexas necessidades de pacientes acompanhados pelo SAD. Aponta os limites da abordagem da biomedicina - centrada no cuidado da doença - para dar conta das necessidades de pessoas em situação de vulnerabilidade. Mostra a importância de atividades de apoio social (serviços domésticos, auxílio ao cuidador em tarefas como higiene, respite care, assistência remota, mobilidade), jurídico (usufruto de direitos, principalmente) entre outros, reforçando o caráter necessariamente intersetorial do cuidado em saúde como historicamente posto pela Saúde Coletiva. Valoriza a perspectiva de pessoas vivendo situação de vulnerabilidade, contribuindo para fortalecer o exercício da alteridade, pela equipe de saúde, que leva em conta o "outro" em toda a sua complexidade.

A pesquisa consegue dar voz tanto para os pacientes atendidos pelo SAD, como para os cuidadores, permitindo vislumbrar um universo de grandes carências e fragilidades que deveriam presidir as açóes governamentais e gerenciais, reforçando o projeto ético de defesa radical da vida, onde ela é mais negada ou pouco reconhecida. Aponta possibilidades, mas também limites, na adoção da abordagem cartográfica, como vem ocorrendo de modo cada vez significativo nos estudos na área da saúde. 
A pesquisa aponta elementos para a caracterização dos desafios que precisam ser enfrentados neste tipo de estudo, em particular a curta permanência do pesquisador no campo, os limites não muito claros do quanto pode intervir na organização do processo de trabalho da equipe e, centralmente, a necessidade de uma permanente análise de implicação, trabalhando, entre outras coisas, as delicadas relaçôes que precisa estabelecer com a gerência e com algumas categorias profissionais, em particular com os médicos.

Como resultado dessa intervenção, provocada pelo método da cartografia, ou seja, a ação do pesquisador com os trabalhadores no campo de pesquisa, houve reflexões sobre a prática e mudanças de posturas dos mesmos, influenciando o cotidiano da atenção domiciliar. E ainda, após a intervenção do grupo focal com as enfermeiras da rede de Atenção Básica, algumas profissionais se dispuseram a rever processos de trabalho em relação à atenção domiciliar em suas unidades de saúde. ${ }^{1}$

\section{Referências}

ALTOÉ, S. (Org.). René Lourau: analista institucional em tempo integral. São Paulo: Hucitec, 2004.

BRASIL. Ministério da Saúde. Portaria GM/MS 1600 de 07 de julho de 2011. Reformula a Política Nacional de Atenção às Urgências e institui a Rede de Atenção às Urgências no Sistema Único de Saúde (SUS). Diário Oficial da Uniāo: Seção 1, Brasília, DF, n. 193, p.69, 8 jul. 2011. Disponível em: http://bvsms.saude.gov.br/bvs/saudelegis/gm/2011/prt1600_07_07_2011.html. Acesso em: 15 jun. 2013. (2011a)

. Ministério da Saúde. Portaria GM/MS 2029 de 24 de agosto de 2011. Institui a Atenção Domiciliar no âmbito do SUS. Diário Oficial da União: Seção 1, Brasília, DF, n. 164, p. 91, 25 ago. 2011. Disponível em: http://bvsms.saude.gov.br/bvs/saudelegis/gm/2011/ prt2029_24_08_2011.html. Acesso em: 16 jun. 2013. (2011b).

. Ministério da Saúde. Portaria GM/MS 825 de 25 de abril de 2016. Redefine a Atenção Domiciliar no âmbito do Sistema Único de Saúde (SUS) e atualiza as equipes habilitadas. Diário Oficial da União: Seção 1, Brasília, DF, n. 78, p.33, 26 abr. 2016. Disponível em: http://www. brasilsus.com.br/images/portarias/abril2016/dia26/portaria825.pdf. Acesso em: 31 out. 2016.

. Ministério da Saúde. Portaria GM/MS de Consolidação nº5 de 28 de setembro de 2017. Consolidaçấo das normas sobre as açôes e os serviços de saúde do Sistema Único de Saúde. Diário Oficial da União: Seção 1, Brasília, DF, n. 190, p.360, 03 out. 2017. Disponível em: http://portalarquivos2.saude.gov.br/images/pdf/2018/marco/29/PRC-5-Portaria-deConsolida----o-n---5--de-28-de-setembro-de-2017.pdf. Acesso em: 02 ago. 2019. 
. Ministério da Saúde. Portaria GM/MS no 1653, de 02 de outubro de 2015. Institui o Sistema de Informação em Saúde para a Atenção Básica (SISAB), com o objetivo de garantir a transição entre o Sistema de Registro das Ações Ambulatoriais de Saúde (RAAS) e o SISAB. Diário Oficial da Uniāo: Seção 1, Brasília, DF, n.150, p. 673, 05 out. 2015. Disponível em: http:// bvsms.saude.gov.br/bvs/saudelegis/gm/2015/prt1653_02_10_2015.html. Acesso em: 19 abr. 2017. BRASIL. Ministério da Saúde. Portaria GM/MS no 4279, de 30 de dezembro de 2010. Estabelece diretrizes para a organização da Rede de Atenção à Saúde no âmbito do Sistema Único de Saúde (SUS). Diário Oficial da União: Seção 1, Brasília, DF, n. 251, p. 88, 31 dez. 2010. Disponível em: http://conselho.saude.gov.br/ultimas_noticias/2011/img/07_jan_portaria4279_301210. pdf. Acesso em: 31 jul.2013.

. Ministério da Saúde. Portaria GM/MS no 963 de 27 de maio de 2013. Redefine a Atenção Domiciliar no âmbito do Sistema Único de Saúde (SUS). Diário Oficial da União: Seção 1, Brasília, DF, n. 101, p. 30, 28 maio 2011. Disponível em: ftp://ftp.saude.sp.gov.br/ ftpsessp/bibliote/informe_eletronico/2013/iels.mai.13/Iels100/U_PT-MS-GM-963_270513. pdf. Acesso em: 25 abr. 2014.

CAMPOS, G.W.S. Um método para análise e co-gestão de coletivos: a constituição do sujeito, a produção de valor de uso e a democracia em instituiçóes: o método da roda. São Paulo: Hucitec, 2000.

CECÍLIO, L.C.O. et al. O agir leigo e o cuidado em saúde: a produção de mapas de cuidado. Cadernos de Saúde Pública. Rio de Janeiro, v. 30, n.7, p. 1502-1514, jul. 2014. Disponível em: https:/www.scielo.br/pdf/csp/v30n7/0102-311X-csp-30-7-1502.pdf. Acesso em: 04 ago. 2017.

DEJOURS, C. et al. Psicodinâmica do Trabalho: contribuiçôes da escola Dejouriana à análise da relação prazer, sofrimento e trabalho. São Paulo: Atlas, 1994.

FEUERWERKER, L.C.; MERHY, E.E. A contribuição da atenção domiciliar para a configuração de redes substitutivas da saúde: desinstitucionalização e transformação de práticas. Revista Panamericana Salud Publica, v. 24, n.3, p. 180- 188, 2008. Disponível em: https:// scielosp.org/article/rpsp/2008.v24n3/180-188/pt/. Acesso em: 09 ago. 2017.

FRANCO, C. M.; FRANCO, T. B. Linhas de cuidado integral: uma proposta de organizaçáo da Rede de Saúde. São Paulo: SES, 2003. Disponível em: http://www.saude.sp.gov.br/resources/ humanizacao/homepage/acesso-rapido/formacao-tecnica-em-acolhimento-na-atencao-basica/ passo_a_passo_linha_de_cuidado.pdf. Acesso em: 17 out. 2016.

GENET, N. et al. Home Care across Europe: Current structure and future challenges. The European Observatory on Health Systems and Policies. Copenhagen: World Health Organization (WHO), 2012. Disponível em: https:/www.euro.who.int/en/publications/ abstracts/home-care-across-europe.-current-structure-and-future-challenges-2012. Acesso em: 9 ago. 2017 . 
. Home care in Europe: a systematic literature review. BMC Health Services Research, v. 11, n. 207, 2011. Disponível em: http://www.biomedcentral.com/1472-6963/11/207. Acesso em: 30 out. 2013.

HAYASHI, M. The care of older people in Japan: myths and realities of Family "care”. 2011. Disponível em: http://www.historyandpolicy.org/policy-papers/papers/the-care-of-olderpeople-in-japan-myths-and-realities-of-family-care. Acesso em: 26 out. 2016.

KASTRUP, V. O funcionamento da atenção no trabalho do cartógrafo. Psicologia e Sociedade. Belo Horizonte, v. 19, n. 1, p.15-22, Jan/Abr. 2007. Disponível em: https://www.scielo.br/pdf/ psoc/v19n1/a03v19n1.pdf. Acesso em: 20 jun. 2015.

KASTRUP, V.; PASSOS, E. Cartografar é traçar um plano comum. Fractal, Rev. Psicologia. Niteroi, v. 25. n.2, p. 263-280, maio/ago. 2013. Disponível em: https://www.scielo.br/pdf/ fractal/v25n2/04.pdf. Acesso em: 09 ago. 2015.

LAPASSADE, G. As microssociologias. Tradução: Lucie Didio. Brasília: Liber Livro Editora, 2005.

MELUCCI, A. Por uma sociologia reflexiva: pesquisa qualitativa e cultura. Tradução: Maria do Carmo Alves do Bomfim. Petrópolis: Vozes, 2005.

MENDES, W. Home Care: uma modalidade de assistência à saúde. Rio de Janeiro: UERJ/ UNATI, 2001. Disponível em: http://www.crde-unati.uerj.br/publicacoes/textos_Unati/ unati4.pdf. Acesso em: 15 out. 2017.

ORGANIZATION FOR ECONOMIC CO-OPERATION AND DEVELOPMENT. Long-term care for older people. Paris: OECD, 2005. Disponível em: https://www.oecdilibrary.org/social-issues-migration-health/the-oecd-health-project_19901291. Acesso em: 10 out. 2017.

ROLNIK, S. Cartografia Sentimental: transformaçóes contemporâneas do desejo. São Paulo: Estação Liberdade, 1989.

SAFFER, D. A.; BARONE, L. R. Em busca do comum: o cuidado do agente comunitário de saúde em Saúde Mental. Physis: Revista de Saúde Coletiva. Rio de Janeiro, v. 27, n. 3, p. 813-833, 2017. Disponível em: cielo.br/pdf/physis/v27n3/1809-4481-physis-27-03-00813.pdf. Acesso em: 21 ago. 2019.

SEADE. Perfil do Município "X" - SP. São Paulo: Fundação SEADE, 2017. Disponível em: http://www.imp.seade.gov.br/frontend/\#/perfil. Acesso em: 19 abr. 2017.

SEIXAS C. T. et al. Experiências de Atenção Domiciliar em Saúde no Mundo: lições para o caso brasileiro. 2013. Disponível em: http://apsredes.org/site2013/atencao-domiciliar/files/2013/12/ Revis\%C3\%A3o-Bibliogr\%C3\%A1fica-FINAL-junho-2013.pdf. Acesso em: 28 set. 2016. 
SOUZA, E.M.; SOUZA, S.P. Cartografia e genealogia: movimentos, processos e devires. In: SOUZA, E.M. (Org.). Metodologias e analíticas qualitativas em pesquisa organizacional: uma abordagem teórico-conceitual. Vitória: EDUFES, 2014, p. 215-238. Disponível em: http://www. unihorizontes.br/fnh/wp-content/uploads/2014/09/Metodologias-e-analíticas-qualitativas-empesquisa-organizacional-uma-abordagem-teórico-conceitual.pdf. Acesso em: 15 nov.2016.

TARRICONE, R.; TSOUROS, A.D. The solid facts: Home Care in Europe. Milano: Università Commerciale Luigi Bocconi/World Health Organization (WHO), 2008.

TORRALBA I ROSELLÓ, F. Antropologia do cuidar. Organização e apresentação: Vera Regina Waldow. Tradução: Guilherme Laurito Summa. Petrópolis: Vozes, 2009.

TORRES, R.D. Governabilidade, governança e poder informal: um problema central de sociologia política. Civitas. Porto Alegre. v.16, n.1, jan-mar. 2016. Disponível em: https://www. scielo.br/pdf/civitas/v16n1/1984-7289-civitas-16-01-0153.pdf. Acesso em: 20 jan 2017.

\section{Nota}

${ }^{1}$ S. Pozzoli elaborou e executou o projeto de pesquisa e analisou os resultados. L. C. O. Cecilio contribuiu com a construção do método de análise dos dados e a interpretação destes, assim como a revisão completa do texto final da pesquisa e do presente artigo. 


\section{Abstract}

\section{Cartography of a home care service and its visibility plans}

Caring for sick people in their homes refers to time immemorial, but due to the aging of the population, there has been an increasing organization of such practice, with home care services. This research work aimed at knowing the care process in the Home Care Service of a medium-sized municipality in the State of São Paulo as a component of the Urgency and Emergency Network. It is a qualitative case study, using cartography in the research field. Interviews were also conducted with caregivers and a hospital nurse, and a focus group with Primary Care nurses. For data analysis, the first approximation of the empirical material was the definition of "cutting plans" and then "visibility plans". Management-related problems were identified; limitations in the use of the information system; isolation of the Home Care Service in relation to other services in the health network; limitations of Primary Care to effectively support the service; caregiver burden; and need for support strategies.

> Keywords: home care services; health services for the elderly; public health policies. 